\title{
Potassium channel activator attenuates salicylate-induced cochlear hearing loss potentially ameliorating tinnitus
} \author{
Jason A. Miranda ${ }^{4}$ and Richard J. Salvi ${ }^{1}$ \\ ${ }^{1}$ Center for Hearing and Deafness, State University of New York at Buffalo, Buffalo, NY, USA \\ 2 Department of Otolaryngology, General Hospital of PLA, Beijing, China \\ ${ }^{3}$ Department of Otolaryngology, Peking University Third Hospital, Beijing, China \\ ${ }^{4}$ Neusentis Research Unit, Pfizer, Cambridge, UK
}

Wei Sun ${ }^{1}$, Jun Liu ${ }^{2}$, Chao Zhang ${ }^{2}$, Na Zhou ${ }^{3}$, Senthilvelan Manohar ${ }^{1}$, Wendy Winchester ${ }^{4}$,

\section{Edited by:}

Jinsheng Zhang, Wayne State

University, USA

Reviewed by:

Huiming Zhang, University of Windsor, Canada

Jian Wang, Dalhousie University, Canada

\section{*Correspondence:}

Wei Sun, Center for Hearing and Deafness, State University of New

York at Buffalo, 137 Cary Hall, Buffalo,

NY 14214, USA

e-mail:weisun@buffalo.edu
High dose sodium salicylate causes moderate, reversible hearing loss and tinnitus. Salicylate-induced hearing loss is believed to arise from a reduction in the electromotile response of outer hair cells (OHCs) and/or reduction of KCNQ4 potassium currents in $\mathrm{OHCs}$, which decreases the driving force for the transduction current. Therefore, enhancing $\mathrm{OHC}$ potassium currents could potentially prevent salicylate-induced temporary hearing loss. In this study, we tested whether opening voltage-gated potassium channels using ICA-105665, a novel small molecule that opens $\mathrm{KCNQ} 2 / 3$ and $\mathrm{KCNO} 3 / 5$ channels, can reduce salicylate-induced hearing loss. We found that systemic application of ICA-105665 at $10 \mathrm{mg} / \mathrm{kg}$ prevented the salicylate-induced amplitude reduction and threshold shift in the compound action potentials recorded at the round window of the cochlea. ICA-105665 also prevented the salicylate-induced reduction of distortion-product otoacoustic emission. These results suggest that ICA-105665 partially compensates for salicylate-induced cochlear hearing loss by enhancing $\mathrm{KCNO} 2 / 3$ and $\mathrm{KCNO} 3 / 5$ potassium currents and the motility of OHCs.

Keywords: salicylate, KCNO, hearing loss, compound action potential, otoacoustic emission

\section{INTRODUCTION}

Aspirin, with sodium salicylate as an active ingredient, is one of the most widely used analgesic, anti-inflammatory, and antipyretic drugs (1). Sodium salicylate at a high dose (1-10 mM) can induce a moderate, reversible cochlear hearing loss ( $20-40 \mathrm{~dB}$ threshold elevation), tinnitus, and suppression of otoacoustic emissions (OAEs) (2, 3). These perceptual changes have generally been attributed to functional impairments in the cochlea such as a down regulation of the electromotile response of outer hair cells (OHCs) and a decrease in neural output of the cochlea (4-9). The effect of salicylate on $\mathrm{OHC}$ electromotility at a high concentration $(>1 \mathrm{mM})$ is likely due to its competition for the chloride anion binding site on the prestin motor protein, rather than plasma membrane mechanics (7). A more recent study found that at moderate concentrations $(0.1-1 \mathrm{mM})$, salicylate also causes a concentration-dependent reversible reduction of a voltage-gated potassium channel, which is encoded by KCNQ4 gene of OHCs (10). This subsequently may depolarize the OHC, which would reduce the net driving force of the transduction current thereby diminishing $\mathrm{OHC}$ electromotility. Thus, there are at least two mechanisms by which salicylate can cause an OHC-based cochlear hearing loss.

KCNQ genes encode a family of five voltage-gated potassium channels, i.e., KCNQ1 through KCNQ5, and KCNQ channel has six transmembrane domains and a single pore loop (11). In the cochlea, all members of the KCNQ family have been identified
$(11,12)$. KCNQ4 channels are expressed on hair cells and spiral ganglion neurons $(13,14)$ and the mutation of KCNQ4 accounts for human non-syndromic deafness DFNA2 an autosomal dominant hearing loss (15). Since the resting potential of $\mathrm{OHC}$ is dependent on potassium currents, KCNQ4 mutation can reduce $I_{\mathrm{K}}$, which leads to selective degeneration of OHCs (16). In addition, KCNQ2 is expressed in the modiolus and organ of corti, synaptic regions under hair cells, spiral ganglion auditory neurons, and nerve fibers innervating hair cells (12). KCNQ3 was detected in the cochlear lateral wall. Although the immunocytochemistry study did not clearly identify KCNQ2/3 on OHCs, M-like currents, which are mediated by KCNQ2/3 and KCNQ3/5 channels (17-20), have been recorded in isolated guinea pig OHCs (21). $\mathrm{M}$-currents are low-threshold depolarization-activated potassium currents that can be inhibited by the cholinergic agonist muscarine (22). M-currents play a role in stabilizing the resting membrane potential, which is important for regulating cellular excitability and $\mathrm{K}+$ homeostasis (23). However, the function of KCNQ2/3 and $\mathrm{KCNQ} 3 / 5$ in salicylate-induced cochlear hearing loss is poorly understood. The recently identified KCNQ5 channels, often coexpressed with KCNQ3 channels, are expressed in the synaptic endings in the auditory brainstem and the calyx terminals of type I vestibular hair cells (24). Therefore, we tested the effects of ICA105665, a novel small molecule that selectively opens KCNQ2/3 and KCNQ3/5 channels (Kv7.2/7.3 and $\operatorname{Kv7.3/7.5)~}(25,26)$ to determine its effects on salicylate-induced hearing loss. 


\section{EXPERIMENTAL PROCEDURES \\ ANIMALS}

Twenty-one adult male Sprague-Dawley rats (3-5 months, 200$400 \mathrm{~g}$ ) were used for the physiological recordings. All protocols were approved by the Institutional Animal Care and Use Committee (IACUC) of the State University of New York at Buffalo that conform to the guidelines issued by the National Institutes of Health. This research minimized the number of animals used and their suffering.

\section{SURGERY}

Rats were anesthetized with a mixture of ketamine $(50 \mathrm{mg} / \mathrm{kg})$ and xylazine $(6 \mathrm{mg} / \mathrm{kg})$. The bulla of the left ear was exposed and a silver ball electrode was placed on the round window (27). Body temperature was measured and maintained using a heating pad (Homeothermic blanket control unit, Harvard Apparatus, MA, USA). Compound action potentials (CAPs) were recorded before and after the delivery of sodium salicylate $(250 \mathrm{mg} / \mathrm{kg}$, i.p.) with/without ICA-105665 (10 mg/kg, i.m.). Since the peak concentration of ICA-105665 occurred $\sim 1 \mathrm{~h}$ after the injection (manuscript in preparation), ICA-105665 was always injected $1 \mathrm{~h}$ before salicylate treatment. Sodium salicylate (S-2679, Sigma, St. Louis, MO, USA) was dissolved in Ringer's solution $(25 \mathrm{mg} / \mathrm{ml})$. ICA-105665 (100 mg) was first dissolved in $50 \mu \mathrm{l}$ of DMSO and $950 \mu \mathrm{l}$ of methylcellulose, and then dissolved in $19 \mathrm{ml}$ of water to make a final ICA- 105665 concentration of $5 \mathrm{mg} / \mathrm{ml}$. This dose resulted in a mean ICA-105665 unbound plasma concentration of $69.1 \mathrm{nM} \pm 9.5 \mathrm{SEM}$, which is a pharmacologically relevant level for selectivity of this compound. The ICA-105665 in vitro EC50 (concentration at which $50 \%$ of the maximum effect is achieved) for cloned rat KCNQ2/3 channels is $160 \mathrm{nM}$ with high selectivity at this exposure level (25) (manuscript in preparation).

\section{ACOUSTICAL STIMULI AND RECORDINGS}

Stimuli were generated with hardware from Tucker-Davis Technologies (TDT, Alachua, FL, USA) and software (SigGen, TDT) and presented through a high frequency speaker (Fostex FT28D, Fostex, Tokyo, Japan). Tone-bursts ( $2 \mathrm{~ms}$ duration and $1 \mathrm{~ms}$ rise/fall) at $4,8,12,16$, and $32 \mathrm{kHz}$ were used to elicit the CAP at intensities ranging from 25 to $95 \mathrm{~dB}$ SPL ( $10 \mathrm{~dB}$ step). Stimuli were calibrated using a sound level meter (824, Larson Davis, Depew, NY, USA) with a half inch microphone (Larson Davis, model \#2559).

The output of the silver ball electrode used to record the CAP was connected to a preamplifier (RA16LA, TDT) using a flexible, low noise cable. The output of the preamplifier was delivered to a digital signal processing module (RX5-2, Pentusa Base Station, TDT) connected to a computer. The electrical response was digitized $(25 \mathrm{kHz})$, filtered $(100-3000 \mathrm{~Hz})$, and averaged $(n=1024)$ over a $10 \mathrm{~ms}$ sampling window.

\section{DPOAE RECORDINGS}

The distortion-product otoacoustic emissions (DPOAE) were recorded in a separate group of rats $(n=8)$ using a Smart DPOAE system (Intelligent Hearing Systems, FL, USA). A pair of continuous tones (F1 and F2) was used to elicit the DPOAE. The F2 testing frequencies were from 4 to $24 \mathrm{kHz}$ and the ratio of $\mathrm{F} 2$ to $\mathrm{F} 1$ was set at 1.2. The F2 testing intensities ranged from 15 to $60 \mathrm{~dB}$ with $5 \mathrm{~dB}$ step (the intensity of $\mathrm{F} 1$ was $10 \mathrm{~dB}$ higher than $\mathrm{F} 2$ ). In four rats, the DPOAEs were recorded prior to and $1 \mathrm{~h}$ after salicylate treatment. In the other four rats, the baseline DPOAEs was recorded and then the rats were treated with ICA-105665 (10 mg/kg, i.m.). One hour after ICA-105665 treatment, DPOAEs were recorded and then the rats were treated with salicylate $(250 \mathrm{mg} / \mathrm{kg}$, i.p. $)$ and DPOAEs were recorded $1 \mathrm{~h}$ afterward.

\section{STATISTIC DATA ANALYSIS}

The graphs and statistical analyses were performed using GraphPad Prism version 5.00 for Windows (GraphPad Software, San Diego, CA, USA) unless otherwise noted. Results are presented as mean \pm SEM.

\section{RESULTS}

\section{ICA-105665 ATTENUATED SALICYLATE'S EFFECT ON COCHLEA}

The threshold and the amplitude of CAPs recorded from the round window of anesthetized rats were monitored before, and at 1 and $2 \mathrm{~h}$ after treatment with salicylate $(250 \mathrm{mg} / \mathrm{kg}$, i.p. $)$ with/without ICA-105665 (10 mg/kg, i.p.). Salicylate treatment caused a large reduction of the CAP amplitude and noticeable threshold shifts. Figure 1A shows typical CAP waveforms recorded before and after
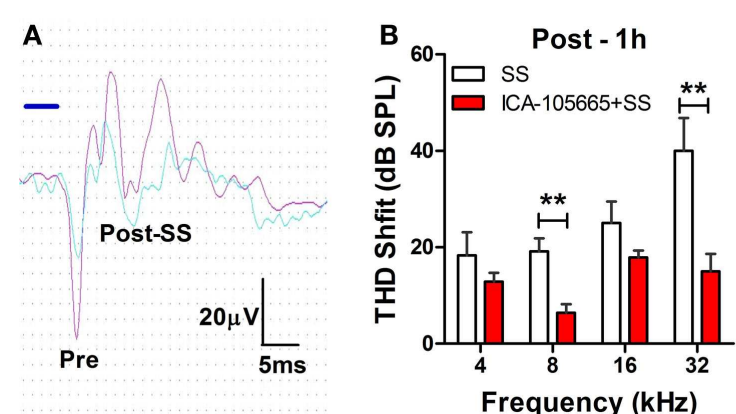

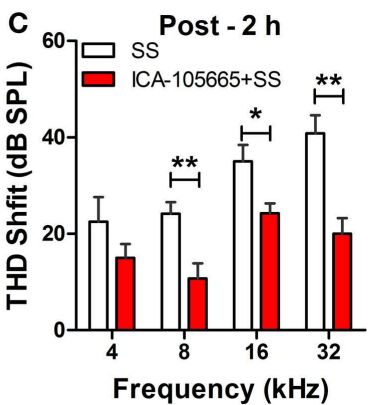

FIGURE 1 | Effects of ICA-105665 on compound action potential (CAP) threshold shifts induced by salicylate (SS). (A) Typical CAP response recorded from the round window of cochlea elicited by a tone-burst stimulus $(8 \mathrm{kHz}, 80 \mathrm{~dB}$ SPL). (B,C) Significant threshold shifts of CAP were induced by high doses of SS (250 mg/kg, i.p.). ICA-105665 (10 mg/kg, i.p., $n=7)$ treatment caused a significant reduction of CAP threshold shifts at 8 , and $32 \mathrm{kHz}$ on $1 \mathrm{~h}$, and 8,16 , and $32 \mathrm{kHz}$ on $2 \mathrm{~h}$ after salicylate injection (Student's $t$-test, $\mathrm{df}=11, P$ values were listed in Table 1) 
salicylate treatment. Figures $\mathbf{1 B}, \mathbf{C}$ show the threshold shifts of the $\mathrm{CAP}$ at 1 and $2 \mathrm{~h}$ after salicylate injection. The CAP threshold significantly increased $1-2 \mathrm{~h}$ after salicylate injection. The average CAP threshold shifts were $18 \pm 4.7,19 \pm 2.7,25 \pm 4.4$, and $40 \pm 6.8 \mathrm{~dB}(n=6)$ at $4,8,16$, and $32 \mathrm{kHz} 1 \mathrm{~h}$ after salicylate injection and slightly less at $2 \mathrm{~h}$. To determine if ICA-105665 could prevent salicylate-induced hearing loss, a separate group of rats were treated with ICA-105665 (10 mg/kg, i.p., $n=7) 1 \mathrm{~h}$ before $250 \mathrm{mg} / \mathrm{kg}$ salicylate administration. One hour after ICA105665 was injected, the CAP threshold showed no obvious shift (the average CAP shift was $0.8 \pm 0.8,6.6 \pm 4.9,6.6 \pm 3.3$, and $2.8 \pm 3.2 \mathrm{~dB}$ at $4,8,16$, and $32 \mathrm{kHz}$, respectively, $n=6$ ). The CAP threshold and amplitude were measured $1-2 \mathrm{~h}$ after salicylate injection. The CAP threshold shifts were $14 \pm 1.7,6.4 \pm 1.5$, $17 \pm 1.7$, and $15 \pm 3.6 \mathrm{~dB}$ at $4,8,16$, and $32 \mathrm{kHz} 1 \mathrm{~h}$ after ICA105666 plus salicylate treatment. There was a significant difference between the salicylate treated group and the ICA-105665 plus salicylate treated group at 8 and $32 \mathrm{kHz}$ on $1 \mathrm{~h}$ and 8,16 , and $32 \mathrm{kHz}$ on $2 \mathrm{~h}$ after salicylate injection (Student's $t$-test, $\mathrm{df}=11$, $P$ values were listed in Table 1 ). There was no significant difference at $4 \mathrm{kHz}$ on 1 and $2 \mathrm{~h}$, and $16 \mathrm{kHz}$ on $1 \mathrm{~h}$ treatment (Table 1).

Table 1 | Student's $t$-test on CAP threshold shifts caused by salicylate (250 mg/kg, i.p.) vs. salicylate plus ICA-105665 (df = 11).

\begin{tabular}{lllll}
\hline & $\mathbf{4 ~ k H z}$ & $\mathbf{8 ~ k H z}$ & $\mathbf{1 6 ~ k H z}$ & $\mathbf{3 2 ~} \mathbf{~ H z}$ \\
\hline 1 h treatment & $P=0.14$ & $P=0.001^{* *}$ & $P=0.06$ & $P=0.006^{*}$ \\
2 h treatment & $P=0.11$ & $P=0.007^{* *}$ & $P=0.017^{*}$ & $P=0.001^{*}$ \\
\hline${ }^{*} P<0.05,{ }^{*} P<0.01$. & & &
\end{tabular}

The CAP amplitudes were measured in both groups before and after salicylate injection (Figures $\mathbf{2 A - H}$ ). The CAP amplitude dropped significantly at $4,8,16$, and $32 \mathrm{kHz}$ after salicylate injection with/without ICA-105665 application $(10 \mathrm{mg} / \mathrm{kg})$. The average amplitude decrease caused by salicylate with/without ICA105665 was evaluated at $95 \mathrm{~dB}$ SPL. Salicylate caused a mean $( \pm \mathrm{SEM}, N=5)$ decrease of $34 \pm 6,61 \pm 7,58 \pm 10$, and $33 \pm 23 \%$ at $4,8,16$, and $32 \mathrm{kHz} 2 \mathrm{~h}$ after salicylate treatment $(n=5)$. In the ICA-105665 plus salicylate group, the CAP mean $( \pm$ SEM, $n=5)$ amplitude decrease at $95 \mathrm{~dB}$ SPL was $27 \pm 7,25 \pm 9,34 \pm 13$, and $36 \pm 16 \%$ decrease $2 \mathrm{~h}$ after salicylate treatment $(n=6)$. Figure 3 shows the mean reduction of CAP amplitude at $95 \mathrm{~dB}$ SPL-induced salicylate with/without ICA-105665 treatment. There was no significant difference between the CAP amplitude reduction in the salicylate alone group with the salicylate plus ICA-105665 group at $1 \mathrm{~h}$ post-treatment (Student's $t$-test, $P>0.05$ ), but there was a significant difference at $8 \mathrm{kHz}$ for the $2 \mathrm{~h}$ treatment groups (Student's $t$-test, $P=0.017, t=2.9, \mathrm{df}=9$ ).

\section{DISTORTION-PRODUCT OTOACOUSTIC EMISSION}

The effects of salicylate, ICA-105665 and ICA-105665 plus salicylate on DPOAE $(4-24 \mathrm{kHz})$, are shown in Figures 4 and 5. Salicylate induced a decrease in DPOAE amplitude at all tested frequencies and more changes were found in the high frequencies. To determine if the ICA-105665 could prevent the salicylate-induced DPOAE decrease, rats were treated with ICA-105665 $(10 \mathrm{mg} / \mathrm{kg}$, i.p., $n=4)$ and then with salicylate $1 \mathrm{~h}$ later. After ICA-105665 plus salicylate treatment, the DPOAE amplitudes were significantly larger than those in the salicylate alone group at 16 and $24 \mathrm{kHz}$ (40-60 dB SPL). Since the increase in DPOAE amplitude with ICA-105665 plus salicylate vs. salicylate alone mainly occurred at higher intensities, we did linear regression analysis
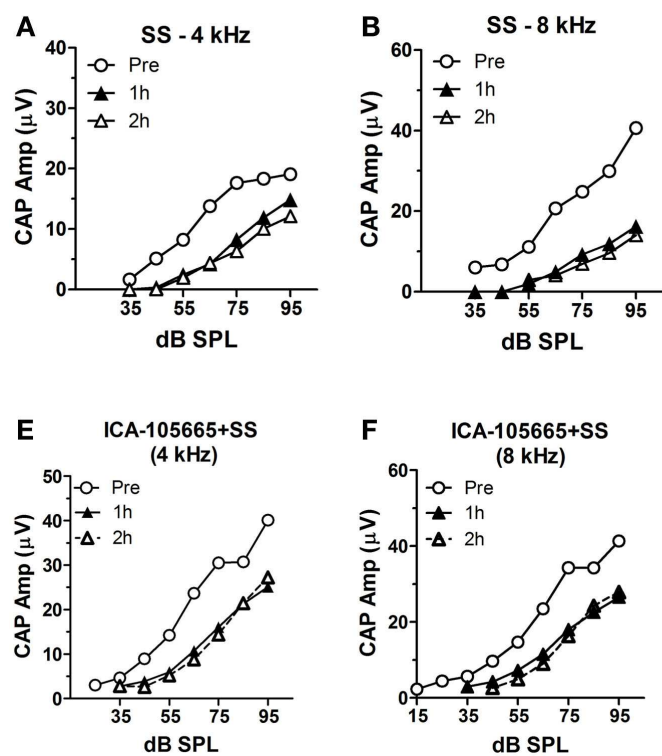
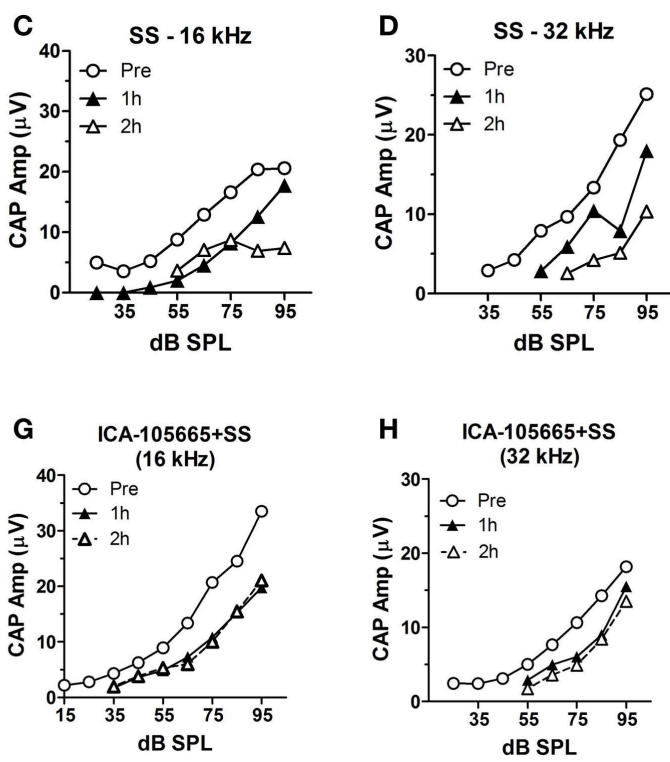

FIGURE 2 |The input-output functions of CAP before and after salicylate treatment with/without ICA-105665. (A-D) The CAP amplitude change induced by salicylate treatment ( $250 \mathrm{mg} / \mathrm{kg}$, i.p.) at 4, 8,16 , and $32 \mathrm{kHz}$. (E-H) The CAP amplitude change caused by salicylate and ICA-105665 (10 mg/kg, i.p., $n=7)$ at 4 , 8,16 , and $32 \mathrm{kHz}$. 

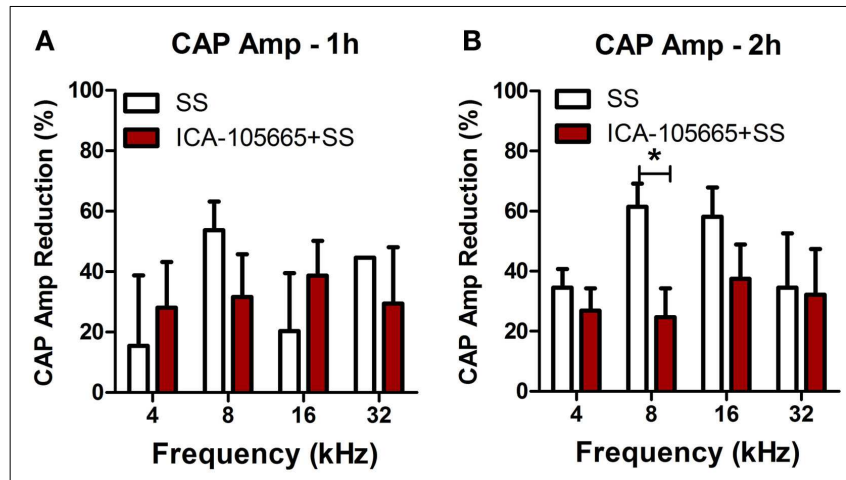

FIGURE 3 | The reduction of CAP amplitude at $95 \mathrm{~dB}$ SPL induced by salicylate with/without ICA-105665 treatment. There was no significant difference between the CAP amplitude reduction in the salicylate alone group with the salicylate plus ICA-105665 group at $1 \mathrm{~h}$ post-treatment $(\mathbf{A}$, Student's $t$-test, $P>0.05)$, but there was a significant difference at $8 \mathrm{kHz}$ for the $2 \mathrm{~h}$ treatment groups (B, Student's $t$-test, $t=2.9, \mathrm{df}=9$ ).
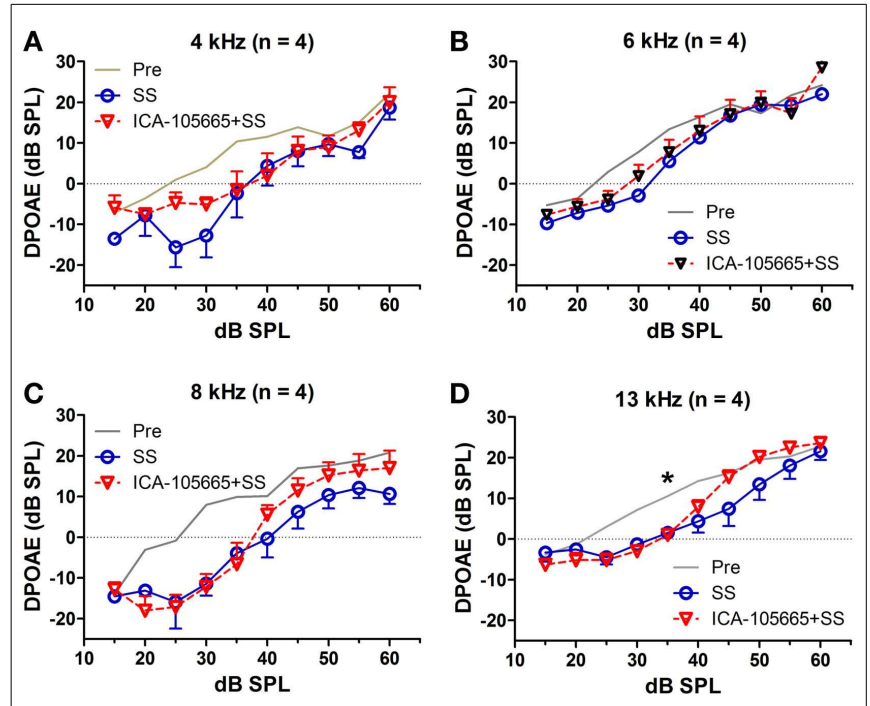

E
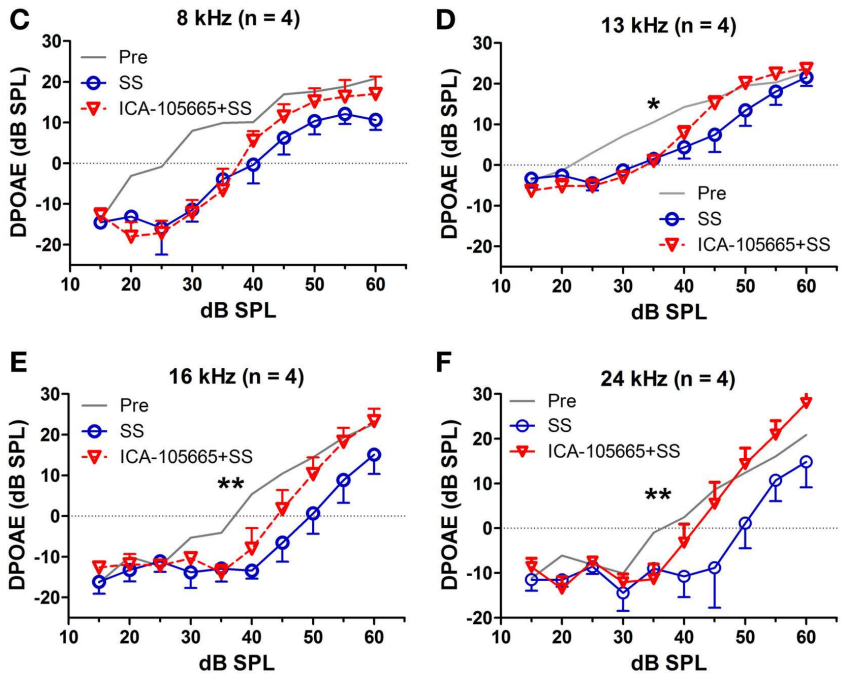

$\mathbf{F}$

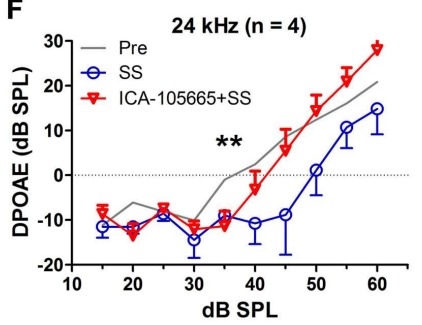

FIGURE 4 |The effects of salicylate and ICA-105665 on the amplitudes of distortion-product otoacoustic emissions (DPOAE). (A-F) Salicylate induced a significant decrease in DPOAE amplitude at all frequencies (4-24 kHz, two-way ANOVA, $P<0.001$ ). Treatment with ICA-105665 prior to salicylate injection lessened the SS-induced DPOAE reductions at high frequencies. The slopes of the DPOAE amplitude-intensity functions before and after the treatment of salicylate with/without ICA-105665 were significant at 13,16 , and $24 \mathrm{kHz}$, but not on 4,6 , and $8 \mathrm{kHz}$ (the $F$ and $P$ values were listed in Table 2).
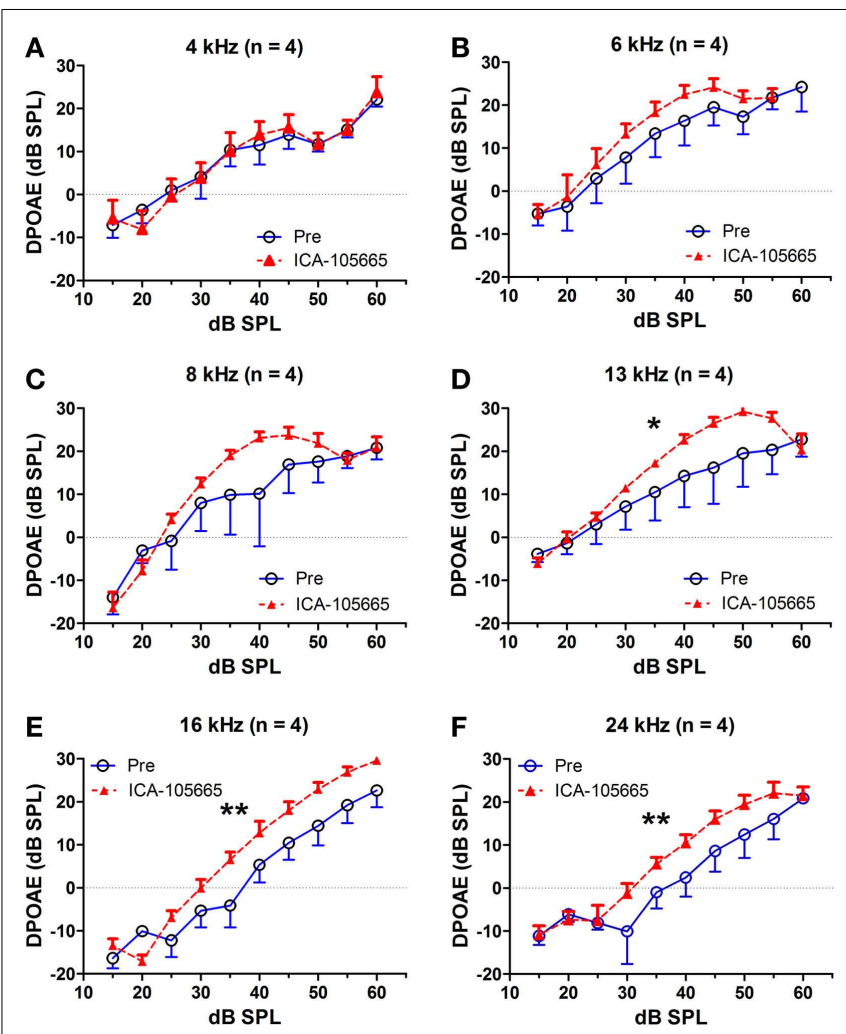

FIGURE 5 | ICA-105665 treatment showed a slight increase on DPOAE amplitudes at high frequencies (D-F), not at low frequencies (A-C). However, the difference was not significant due to the small sample size.

on the DPOAE amplitude-intensity function at $40-60 \mathrm{~dB}$ SPL for each animal on each frequency. The slopes of the DPOAE amplitude-intensity functions were used for statistical analysis. We found that the slope of the DPOAE amplitude-intensity function (40-60 dB SPL) before and after the treatment of salicylate with/without ICA-105665 were significantly different at 13,16 , and $24 \mathrm{kHz}$, but not on 4,6 , and $8 \mathrm{kHz}$ (the $F$ and $P$ values were listed in Table 2). Figure 5 showed that after ICA- 105665 treatment, the DPOAE amplitude showed a slight increase. However, post Tukey's tests showed a significant difference at 13,16, and $24 \mathrm{kHz}$ between before and after SS with/without ICA- 105665 treatment. This difference was likely caused by the effect of ICA105665, which enhanced the amplitude of DPOAE. There was no significant difference between before and after ICA-105665 treatment. This may be due to the small sample size has been tested in the experiment.

\section{DISCUSSION}

Salicylate-induced sensorineural hearing loss is mainly caused by down regulation of the electromotile response of OHCs, which decreases the neural output of cochlea (4-9). In our experiment, we found that the activation of cochlear potassium channels using ICA-105665, an activator of KCNQ2/3 and KCNQ3/5 channels, can decrease salicylate-induced CAP amplitude reduction and threshold shifts. Since ICA-105665 also caused an 
Table 2 | One-way ANOVA test on the slopes of DPOAE amplitude-intensity function (40-60 dB SPL) before and after the treatment of salicylate (SS) with/without ICA-105665

\begin{tabular}{|c|c|c|c|c|c|c|c|}
\hline & Pre & sS & SS + ICA & ICA & df & $\boldsymbol{F}$ & $P$ \\
\hline $4 \mathrm{kHz}$ & $0.44 \pm 0.20$ & $0.56 \pm 0.12$ & $0.38 \pm 0.08$ & $0.82 \pm 0.19$ & 3,15 & 2.58 & 0.12 \\
\hline $6 \mathrm{kHz}$ & $0.35 \pm 0.27$ & $0.47 \pm 0.12$ & $0.62 \pm 0.20$ & $0.28 \pm 0.12$ & 3,15 & 0.89 & 0.47 \\
\hline $8 \mathrm{kHz}$ & $0.46 \pm 0.50$ & $0.55 \pm 0.17$ & $0.55 \pm 0.17$ & $-0.2 \pm 0.05$ & 3,15 & 1.49 & 0.28 \\
\hline $13 \mathrm{kHz}$ & $0.42 \pm 0.25$ & $0.90 \pm 0.10$ & $0.77 \pm 0.13$ & $-0.07 \pm 0.15$ & 3,15 & 5.81 & $0.01 *$ \\
\hline $16 \mathrm{kHz}$ & $0.86 \pm 0.05$ & $1.44 \pm 0.21$ & $1.58 \pm 0.12$ & $0.84 \pm 0.09$ & 3,15 & 10.58 & $0.002 * *$ \\
\hline $24 \mathrm{kHz}$ & $0.88 \pm 0.19$ & $1.41 \pm 0.12$ & $1.55 \pm 0.18$ & $0.56 \pm 0.07$ & 3,15 & 8.04 & $0.006^{* *}$ \\
\hline
\end{tabular}

${ }^{*} P<0.05,{ }^{*} P<0.01$.

increase of DPOAE amplitude, our study suggests that ICA-105665 can compensate for salicylate-induced hearing loss presumably by enhancing the electromotility of $\mathrm{OHC}$ through activating potassium currents.

KCNQ2, KCNQ3, and KCNQ5 are co-expressed in many regions of the cochlea $(11,28)$, including OHCs, spiral ganglion neurons, and the lateral wall of the cochlea $(12,15) . \mathrm{KCNQ} 2 / 3$ and $\mathrm{KCNQ} 3 / 5$ are heteromeric channels that may underlie $\mathrm{M}$-currents, which are important in maintaining neuronal excitability (17). Mlike currents have been recorded in isolated OHCs in the guinea pig cochlea (21). These currents can be activated at more depolarized potentials than other voltage-gated $\mathrm{K}+$ channels and may be involved in maintaining auditory excitability. We found that activation of KCNQ2/3 and KCNQ3/5 enhanced DPOAE amplitude; these results suggest that activation of M-channel-mediated potassium currents may be involved in electromotility of OHCs. The enhancements of DPOAE amplitude by ICA- 105665 were significant at high, but not low frequencies. This suggests that more KCNQ channels are expressed in the basal than the apical turn of cochlea. The expression of KCNQ4 in the IHCs and spiral ganglion neurons decreased from the base to the apex of the cochlea (13). However, there is no report on the gradient of KCNQ2, KCNQ3, or KCNQ5 expression in the cochlea. Since ICA-105665 can activate both KCNQ2/3 and KCNQ3/5 channels, it is unclear whether one channel or the other is responsible for effects on CAP and DPOAE or whether a combined effect is driving these differences.

KCNQ2/3 and KCNQ5 are also broadly expressed in the brain, including hippocampus, caude-putamen, globus pallidus, cortex, thalamus, hypothalamus, and midbrain cortex (18, 29-31). Reduction of KCNQ-mediated currents can increase neuronal excitability to epileptogenic levels and cause convulsion (32). KCNQ2/3 openers, such as ICA-27243, can shift the activation of KCNQ2/3 to a hyperpolarized potential and prevent epilepsy (33). ICA-105665, a new generation of anti-seizure drug targeting KCNQ2/3 channels, was tested for efficacy in several epilepsy models because of its selectivity for potassium channels $(25,26)$. Unlike other anti-seizure drugs such as retigabine, which also potentiate GABAa receptor response at slightly higher concentrations, ICA-105665 is more selective and does not affect GABAa receptor responses (33). A recent clinical study reported that ICA105665 at single doses of 100-500 mg reduced photoparoxysmal responses elicited by $2-60 \mathrm{~Hz}$ light flash in patients with epilepsy (34). In our preliminary studies, we also found that ICA-105665 can directly affect the firing properties of neurons in the auditory cortex and the inferior colliculus. However, ICA-105665 failed to reduce salicylate-induced hyperexcitability in the auditory cortex, which suggests that ICA-105665 and salicylate may target different receptors and channels in the central auditory system (data not included).

In summary, ICA-105665, an activator of KCNQ2/3 and KCNQ3/5 channels, reduced the toxic effects of salicylate on the amplitude of the CAP and DPOAE. Since ICA-105665 alone enhanced the amplitude of DPOAEs, we speculate that the drug exerts its protective effects against salicylate ototoxicity by targeting the KCNQ2/3 and or KCNQ3/5 channels. ICA-105665 may be a useful compound in protecting against ototoxicity and noise exposure by enhancing the $\mathrm{OHC}$ motility.

\section{REFERENCES}

1. Akhavan A, Bershad S. Topical acne drugs: review of clinical properties, systemic exposure, and safety. Am J Clin Dermatol (2003) 4:473-92. doi:10.2165/ 00128071-200304070-00004

2. McFadden D, Plattsmier HS, Pasanen EG. Aspirin-induced hearing loss as a model of sensorineural hearing loss. Hear Res (1984) 16:251-60. doi:10.1016/ 0378-5955(84)90114-X

3. Cazals Y. Auditory sensori-neural alterations induced by salicylate. Prog Neurobiol (2000) 62:583-631. doi:10.1016/S0301-0082(00)00027-7

4. Brownell WE. Outer hair cell electromotility and otoacoustic emissions. Ear Hear (1990) 11:82-92. doi:10.1097/00003446-199004000-00003

5. Tunstall MJ, Gale JE, Ashmore JF. Action of salicylate on membrane capacitance of outer hair cells from the guinea-pig cochlea. J Physiol (1995) 485:739-52. doi:10.1113/jphysiol.1995.sp020765

6. Muller M, Klinke R, Arnold W, Oestreicher E. Auditory nerve fibre responses to salicylate revisited. Hear Res (2003) 183:37-43. doi:10.1016/S0378-5955(03) 00217-X

7. Ermilov SA, Murdock DR, El-Daye D, Brownell WE, Anvari B. Effects of salicylate on plasma membrane mechanics. J Neurophysiol (2005) 94:2105-10. doi:10.1152/jn.00414.2005

8. Zhi M, Ratnanather JT, Ceyhan E, Popel AS, Brownell WE. Hypotonic swelling of salicylate-treated cochlear outer hair cells. Hear Res (2007) 228:95-104. doi:10.1016/j.heares.2007.02.007

9. Ruel J, Chabbert C, Nouvian R, Bendris R, Eybalin M, Leger CL, et al. Salicylate enables cochlear arachidonic-acid-sensitive NMDA receptor responses. J Neurosci (2008) 28:7313-23. doi:10.1523/JNEUROSCI.5335-07.2008

10. Wu T, Lv P, Kim HJ, Yamoah EN, Nuttall AL. Effect of salicylate on KCNQ4 of the guinea pig outer hair cell. J Neurophysiol (2010) 103:1969-77. doi:10.1152/ jn.01057.2009

11. Liang GH, Jin Z, Ulfendahl M, Jarlebark L. Molecular analyses of KCNQ15 potassium channel mRNAs in rat and guinea pig inner ears: expression, cloning, and alternative splicing. Acta Otolaryngol (2006) 126:346-52. doi:10. 1080/00016480500416777 
12. Jin Z, Liang GH, Cooper EC, Jarlebark L. Expression and localization of K channels KCNQ2 and KCNQ3 in the mammalian cochlea. Audiol Neurootol (2009) 14:98-105. doi:10.1159/000158538

13. Beisel KW, Nelson NC, Delimont DC, Fritzsch B. Longitudinal gradients of KCNQ4 expression in spiral ganglion and cochlear hair cells correlate with progressive hearing loss in DFNA2. Brain Res Mol Brain Res (2000) 82:137-49. doi:10.1016/S0169-328X(00)00204-7

14. Kharkovets T, Hardelin JP, Safieddine S, Schweizer M, El-Amraoui A, Petit C, et al. KCNQ4, a K+ channel mutated in a form of dominant deafness, is expressed in the inner ear and the central auditory pathway. Proc Natl Acad Sci U S A (2000) 97:4333-8. doi:10.1073/pnas.97.8.4333

15. Kharkovets T, Dedek K, Maier H, Schweizer M, Khimich D, Nouvian R, et al. Mice with altered KCNQ4 $\mathrm{K}+$ channels implicate sensory outer hair cells in human progressive deafness. EMBOJ (2006) 25:642-52. doi:10.1038/sj.emboj.7600951

16. Holt JR, Stauffer EA, Abraham D, Geleoc GS. Dominant-negative inhibition of M-like potassium conductances in hair cells of the mouse inner ear. J Neurosci (2007) 27:8940-51. doi:10.1523/JNEUROSCI.2085-07.2007

17. Wang HS, Pan Z, Shi W, Brown BS, Wymore RS, Cohen IS, et al. KCNQ2 and KCNQ3 potassium channel subunits: molecular correlates of the M-channel. Science (1998) 282:1890-3. doi:10.1126/science.282.5395.1890

18. Schroeder BC, Hechenberger M, Weinreich F, Kubisch C, Jentsch TJ. KCNQ5, a novel potassium channel broadly expressed in brain, mediates M-type currents. J Biol Chem (2000) 275:24089-95. doi:10.1074/jbc.M003245200

19. Selyanko AA, Delmas P, Hadley JK, Tatulian L, Wood IC, Mistry M, et al. Dominant-negative subunits reveal potassium channel families that contribute to M-like potassium currents. J Neurosci (2002) 22:RC212.

20. Brown DA, Passmore GM. Neural KCNQ (Kv7) channels. Br J Pharmacol (2009) 156:1185-95. doi:10.1111/j.1476-5381.2009.00111.x

21. Liang G, Moore EJ, Ulfendahl M, Rydqvist B, Jarlebark L. An M-like potassium current in the guinea pig cochlea. ORL J Otorhinolaryngol Relat Spec (2005) 67:75-82. doi:10.1159/000085439

22. Brown DA, Adams PR. Muscarinic suppression of a novel voltage-sensitive $\mathrm{K}+$ current in a vertebrate neurone. Nature (1980) 283:673-6. doi:10.1038/ $283673 \mathrm{a} 0$

23. Buniel M, Glazebrook PA, Ramirez-Navarro A, Kunze DL. Distribution of voltage-gated potassium and hyperpolarization-activated channels in sensory afferent fibers in the rat carotid body. J Comp Neurol (2008) 510:367-77. doi: $10.1002 / \mathrm{cne} .21796$

24. Caminos E, Garcia-Pino E, Martinez-Galan JR, Juiz JM. The potassium channel KCNQ5/Kv7.5 is localized in synaptic endings of auditory brainstem nuclei of the rat. J Comp Neurol (2007) 505:363-78. doi:10.1002/cne.21497

25. Bialer M, Johannessen SI, Levy RH, Perucca E, Tomson T, White HS. Progress report on new antiepileptic drugs: a summary of the tenth Eilat conference (EILAT X). Epilepsy Res (2010) 92:89-124. doi:10.1016/j.eplepsyres.2010.09.001

26. Bialer M, Johannessen SI, Levy RH, Perucca E, Tomson T, White HS. Progress report on new antiepileptic drugs: a summary of the eleventh Eilat conference (EILAT XI). Epilepsy Res (2013) 103:2-30. doi:10.1016/j.eplepsyres.2012.10.001
27. Sun W, Ding D, Reyes S, Salvi RJ. Effects of AC and DC stimulation on chinchilla SOAE amplitude and frequency. Hear Res (2000) 150:137-48. doi:10.1016/ S0378-5955(00)00195-7

28. Kubisch C, Schroeder BC, Friedrich T, Lutjohann B, El-Amraoui A, Marlin S, et al. KCNQ4, a novel potassium channel expressed in sensory outer hair cells, is mutated in dominant deafness. Cell (1999) 96:437-46. doi:10.1016/S00928674(00)80556-5

29. Biervert C, Schroeder BC, Kubisch C, Berkovic SF, Propping P, Jentsch TJ, et al. A potassium channel mutation in neonatal human epilepsy. Science (1998) 279:403-6. doi:10.1126/science.279.5349.403

30. Weber YG, Geiger J, Kampchen K, Landwehrmeyer B, Sommer C, Lerche H. Immunohistochemical analysis of KCNQ2 potassium channels in adult and developing mouse brain. Brain Res (2006) 1077:1-6. doi:10.1016/j.brainres. 2006.01.023

31. Kanaumi T, Takashima S, Iwasaki H, Itoh M, Mitsudome A, Hirose S. Developmental changes in KCNQ2 and KCNQ3 expression in human brain: possible contribution to the age-dependent etiology of benign familial neonatal convulsions. Brain Dev (2008) 30:362-9. doi:10.1016/j.braindev.2007.11.003

32. Schroeder BC, Kubisch C, Stein V, Jentsch TJ. Moderate loss of function of cyclicAMP-modulated KCNQ2/KCNQ3 K+ channels causes epilepsy. Nature (1998) 396:687-90. doi:10.1038/25367

33. Wickenden AD, Krajewski JL, London B, Wagoner PK, Wilson WA, Clark S, et al. N-(6-chloro-pyridin-3-yl)-3,4-difluoro-benzamide (ICA-27243): a novel, selective KCNQ2/Q3 potassium channel activator. Mol Pharmacol (2008) 73:977-86. doi:10.1124/mol.107.043216

34. Kasteleijn-Nolst Trenite DG, Biton V, French JA, Abou-Khalil B, Rosenfeld WE, Diventura B, et al. Kv7 potassium channel activation with ICA-105665 reduces photoparoxysmal EEG responses in patients with epilepsy. Epilepsia (2013) 54:1437-43. doi:10.1111/epi.12224

Conflict of Interest Statement: The authors declare that the research was conducted in the absence of any commercial or financial relationships that could be construed as a potential conflict of interest.

Received: 19 December 2014; accepted: 20 March 2015; published online: 07 April 2015. Citation: Sun W, Liu J, Zhang C, Zhou N, Manohar S, Winchester W, Miranda $J A$ and Salvi RJ (2015) Potassium channel activator attenuates salicylate-induced cochlear hearing loss potentially ameliorating tinnitus. Front. Neurol. 6:77. doi: 10.3389/fneur.2015.00077

This article was submitted to Neuro-otology, a section of the journal Frontiers in Neurology.

Copyright (c) 2015 Sun, Liu, Zhang, Zhou, Manohar, Winchester, Miranda and Salvi. This is an open-access article distributed under the terms of the Creative Commons Attribution License (CC BY). The use, distribution or reproduction in other forums is permitted, provided the original author(s) or licensor are credited and that the original publication in this journal is cited, in accordance with accepted academic practice. No use, distribution or reproduction is permitted which does not comply with these terms. 